\title{
Dose-, time-, and tissue-dependent effects of 5-bromo-2' -deoxyuridine on the in-vitro organogenesis of Arabidopsis thaliana
}

\author{
Munetaka Sugiyama $\cdot$ Kenro Imamura
}

Received: 11 May 2006/ Accepted: 31 May 2006/Published online: 4 July 2006

(C) Springer Science+Business Media B.V. 2006

\begin{abstract}
Vigorous organogenesis can be induced from hypocotyl and root explants of Arabidopsis thaliana using a two-step culture procedure consisting of preculture on callusinducing medium (CIM) and subsequent culture on shoot-inducing medium (SIM) or root-inducing medium (RIM). With this culture system, we examined the influence of 5-bromo-2'-deoxyuridine (BrdU), a thymidine (dT) analogue, on plant organogenesis in vitro. Treatment with BrdU during SIM or RIM culture had negative effects on shoot and root redifferentiation over a broad range of concentrations. When explants were exposed to low concentrations of BrdU during preculture and then transferred onto BrdU-free SIM, shoot redifferentiation was accelerated significantly. At higher doses, BrdU treatment during the pre-culture inhibited shoot redifferentiation strongly in hypocotyl explants, but not in root explants. This suggests that a target of the BrdU action lies within the process of acquisition of cell proliferation competence specifically involved in hypocotyl dedifferentiation. These effects of BrdU were counteracted by the simultaneous addition of excess dT. BrdU-
\end{abstract}

M. Sugiyama $(\bowtie) \cdot K$. Imamura

Botanical Gardens, Graduate School of Science,

The University of Tokyo, Hakusan 3-7-1,

Bunkyo-ku, Tokyo 112-0001, Japan

e-mail: sugiyama@ns.bg.s.u-tokyo.ac.jp pretreated and untreated explants did not differ significantly in the phytohormone dependency of shoot redifferentiation. Our results provide a basis for future studies on plant organogenesis combining pharmacological analysis with BrdU as a probe and molecular genetics with Arabidopsis mutants.

Keywords 5-bromo-2'-deoxyuridine . dedifferentiation $\cdot$ root redifferentiation $\cdot$ shoot redifferentiation $\cdot$ Arabidopsis
Abbreviations
BrdU 5-bromo-2'-deoxyuridine
CIM callus-inducing medium
2,4-D 2,4-dichlorophenoxyacetic acid
dT thymidine
GM germination medium
IAA indole-3-acetic acid
2-iPA $\quad N^{6}-\left(\Delta^{2}\right.$-isopentenyl)adenine
RIM root-inducing medium
SIM shoot-inducing medium

\section{Introduction}

5-Bromo-2'-deoxyuridine (BrdU) is a structural analogue of thymidine (dT) widely used for 
various purposes in cellular and molecular biological research. The most popular use of BrdU is as a tracer of DNA synthesis. BrdU taken up by cells is phosphorylated and incorporated into DNA in place of dT. Its DNA residues can be detected with the anti-BrdU antibody, and the immunological detection of BrdU incorporation provides a good index of DNA synthesis (Gratzner, 1982). BrdU is also utilized for densitylabeling DNA because the substitution of BrdU for dT increases the buoyant density of DNA fragments (Luk and Bick, 1977).

The other well-known use of BrdU is as a DNA photosensitizer. BrdU substitution of dT in DNA sensitizes it to near-UV light, and cells with BrdU-substituted DNA cannot survive after exposure to near-UV light (Boyce and Setlow, 1963). This characteristic of BrdU is applied to the efficient selection of auxotrophic or conditional mutant cells that do not proliferate and thus do not incorporate BrdU under restrictive conditions (Puck and Kao, 1967). If DNA excision repair takes place in the presence of $\mathrm{BrdU}$, $\mathrm{BrdU}$ is incorporated into repair patches, the photolysis of which allows the estimation of the number of repair sites by measuring single-strand breaks (Regan et al., 1971).

In the aforementioned applications, the physiological effects of BrdU are not usually taken into account. In fact, BrdU is not physiologically neutral: rather, it is cytotoxic (reviewed by Morris, 1991). In some cases, BrdU has a dramatic influence on specific aspects of development. The most striking examples of such BrdU effects in animals include the inhibition of programmed cell death in chick limbs resulting in the formation of web-like structures (Toné et al., 1983), and the induction of anomalies in the brain development of male rats resulting in the impairment of masculine sexual behavior (Kuwagata et al., 2001).

Various developmental effects of BrdU have also been reported in plants. These include the promotion of flowering in Arabidopsis thaliana grown in vitro (Gotô and Hamada, 1988), the interruption of somatic embryogenesis in suspension cultures of Daucus carota (Thomas et al., 1989), and the suppression of transdifferentiation into tracheary elements of isolated mesophyll cells of Zinnia elegans (Shoji et al., 1996). Such BrdU effects were observed at relatively low concentrations, where basic cellular activities such as cell proliferation were not inhibited strongly.

In consideration of these peculiar BrdU effects, BrdU can potentially be utilized as a powerful tool for the pharmacological analysis of plant development, especially in tissue culture. We have investigated genetically organogenesis in vitro employing various temperature-sensitive mutants of Arabidopsis (Yasutani et al., 1994; Ozawa et al., 1998; Sugiyama, 2003; Konishi and Sugiyama, 2003). In the present study, we examined the influence of BrdU on morphogenic responses in tissue culture of Arabidopsis to introduce $\mathrm{BrdU}$ as a pharmacological probe in this line of research. Here, we report dose-, time-, and tissue-dependent effects of BrdU that include both the acceleration and inhibition of shoot redifferentiation. Possible target processes of BrdU will be discussed using comparisons of BrdU effects with phenotypes of the temperaturesensitive mutants.

\section{Materials and methods}

\section{Plant material}

The Landsberg erecta strain of Arabidopsis thaliana (L.) Heynh. was used for all experiments.

Tissue culture

Donor seedlings were aseptically grown on germination medium (GM) under continuous weak light from fluorescent lamps (approximately $10 \mu \mathrm{mol} \mathrm{m} \mathrm{m}^{-2} \mathrm{~s}^{-1}$ ) at $22^{\circ} \mathrm{C}$ for 7 days. Hypocotyl segments (5 mm long) and root segments $(5 \mathrm{~mm}$ long, $5 \mathrm{~mm}$ apart from the hypocotyl/root junction) were excised from the donor plants and placed on callus-inducing medium (CIM). After 4 days of preculture on the CIM, explants were transferred onto shoot-inducing medium (SIM) or root-inducing medium (RIM) for the induction of organogenesis. Unless otherwise indicated, tissue culture was carried out at $22{ }^{\circ} \mathrm{C}$ under continuous weak light (approximately $10 \mu \mathrm{mol} \mathrm{m} \mathrm{s}^{-2}$ ). Tissue culture experiments were repeated at least several times to confirm the reproducibility of the results. 
Culture media

The culture media used here were slightly modified versions of the media of Valvekens et al. (1988), the composition of which was previously described by Ozawa et al. (1998). The GM was MS medium (Murashige and Skoog, 1962) supplemented with $1.0 \%(\mathrm{w} / \mathrm{v})$ sucrose. The CIM was B5 medium (Gamborg et al., 1968) supplemented with $2.0 \%(\mathrm{w} / \mathrm{v})$ glucose, $0.5 \mathrm{mg} \mathrm{l}^{-1} 2,4-\mathrm{D}$, and $0.1 \mathrm{mg} \mathrm{l}^{-1}$ kinetin. The SIM was B5 medium supplemented with $2.0 \%(\mathrm{w} / \mathrm{v})$ glucose, $0.15 \mathrm{mg} \mathrm{l}^{-1}$ IAA, and $0.5 \mathrm{mg} \mathrm{l}^{-1}$ 2-iPA, and the RIM was B5 medium supplemented with $2.0 \%(\mathrm{w} / \mathrm{v})$ glucose and $0.5 \mathrm{mg} \mathrm{l}^{-1}$ indole-3-butyric acid. All media were buffered with $2.3 \mathrm{mM}$ 2-morpholinoethanesulfonic acid (pH 5.7), and solidified with $0.25 \%$ $(\mathrm{w} / \mathrm{v})$ gellan gum.

\section{Results}

\section{Effects of BrdU treatment during SIM or RIM} culture

To assess the effects of continuous application of BrdU on organogenesis in vitro, we first cultured root and hypocotyl explants on SIM or RIM containing various concentrations of BrdU following preculture on CIM without BrdU. Over a broad range of concentrations, BrdU administered in this way had a negative influence on all types of organogenesis tested, i.e., shoot redifferentiation from root explants, shoot redifferentiation from hypocotyl explants, and root redifferentiation from hypocotyl explants (Table 1). Among these organogeneses, the most BrdU-sensitive was shoot redifferentiation from root explants, which was partly inhibited at $1 \mu \mathrm{M}$ and completely inhibited at $10 \mu \mathrm{M}$ or over.

\section{Effects of BrdU treatment during preculture on CIM}

In the second series of experiments, we precultured root and hypocotyl explants on CIM containing various concentrations of BrdU. These explants were then transferred to BrdU-free SIM or RIM to examine the effects of temporal
Table 1 Effects of BrdU treatment at various concentrations during SIM or RIM culture on organogenesis

\begin{tabular}{|c|c|c|c|c|}
\hline \multirow[t]{2}{*}{ Explants } & \multirow[t]{2}{*}{$\begin{array}{l}\text { Type } \\
\text { of organogenesis }\end{array}$} & \multirow[t]{2}{*}{$\begin{array}{l}\text { BrdU } \\
(\mu \mathrm{M})\end{array}$} & \multicolumn{2}{|c|}{$\begin{array}{l}\text { Frequency of } \\
\text { organogene- } \\
\text { sis }(\%)^{\mathrm{a}}\end{array}$} \\
\hline & & & $14 \mathrm{~d}$ & $21 \mathrm{~d}$ \\
\hline \multirow[t]{4}{*}{ Root } & \multirow{4}{*}{$\begin{array}{l}\text { Shoot } \\
\quad \text { redifferentiation }\end{array}$} & 0 & 21.7 & 98.3 \\
\hline & & 1 & 17.5 & 55.0 \\
\hline & & 10 & 0.0 & 0.0 \\
\hline & & 100 & 0.0 & 0.0 \\
\hline \multirow[t]{4}{*}{ Hypocotyl } & \multirow{4}{*}{$\begin{array}{l}\text { Shoot } \\
\quad \text { redifferentiation }^{\mathrm{b}}\end{array}$} & 0 & 86.4 & 100.0 \\
\hline & & 1 & 87.2 & 97.4 \\
\hline & & 10 & 3.4 & 5.1 \\
\hline & & 100 & 0.0 & 0.0 \\
\hline \multirow[t]{4}{*}{ Hypocotyl } & \multirow{4}{*}{$\begin{array}{l}\text { Root } \\
\quad \text { redifferentiation }{ }^{c}\end{array}$} & 0 & 100.0 & 100.0 \\
\hline & & 1 & 100.0 & 100.0 \\
\hline & & 10 & 69.0 & 72.4 \\
\hline & & 100 & 0.0 & 0.0 \\
\hline
\end{tabular}

Root and hypocotyl explants were precultured on CIM without BrdU for 4 days and subsequently cultured on SIM or RIM containing various concentrations of BrdU

${ }^{a}$ Percentages of explants undergoing organogenesis per total explants (38-60 explants for each culture condition) were scored 14 days and 21 days after transfer to SIM or RIM

${ }^{\mathrm{b}}$ Culture on SIM

${ }^{c}$ Culture on RIM

exposure to BrdU before the induction of organogenesis. At concentrations from $1 \mu \mathrm{M}$ to $10 \mu \mathrm{M}$, BrdU pretreatment accelerated shoot redifferentiation in both root and hypocotyl explants (Figure 1a, 1b, 2a, and 2b). At higher doses, whereas BrdU pretreatment inhibited shoot redifferentiation very strongly in hypocotyl explants, such negative effects were not evident in root explants. Root redifferentiation in hypocotyl explants was suppressed by pretreatment with $\mathrm{BrdU}$ at concentrations higher than $3 \mu \mathrm{M}$ (Figure 1c and 2c). All these effects of BrdU pretreatment were counteracted by excess dT added to the CIM simultaneously with BrdU (Table 2).

The effects of BrdU pretreatment on shoot redifferentiation were also compared under different light conditions (Table 3 ). In both root and hypocotyl explants, light was indispensable for the full induction of shoot redifferentiation. The light requirement was more prominent in root explants. Although root explants redifferentiated 
(a) Shoot redif. from root explants

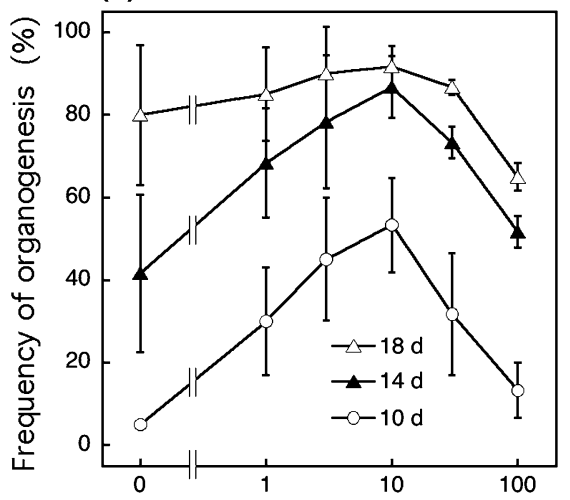

(b) Shoot redif. from hypocotyl explants

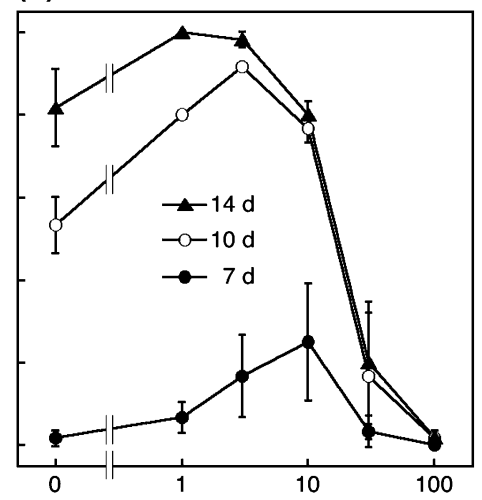

(c) Root redif. from hypocotyl explants

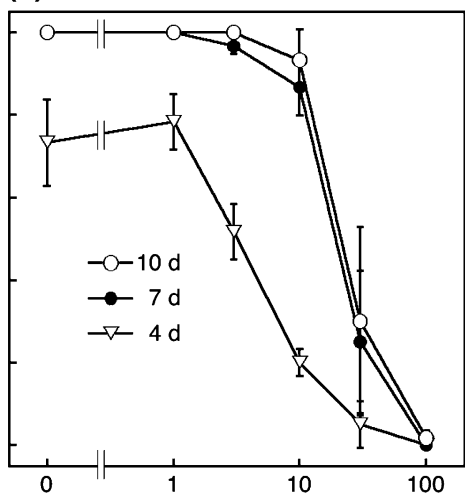

Concentration of $\mathrm{BrdU}(\mu \mathrm{M})$

Fig. 1 Effects of BrdU pretreatment at various concentrations on three types of in-vitro organogenesis. (a) Shoot redifferentiation from root explants. (b) Shoot redifferentiation from hypocotyl explants. (c) Root redifferentiation from hypocotyl explants. Root explants $(a)$ and hypocotyl explants $(b, c)$ were precultured on CIM containing various concentrations of $\mathrm{BrdU}$ for 4 days, and subse- quently cultured on BrdU-free $\operatorname{SIM}(a, b)$ or BrdU-free RIM (c). Frequency of organogenesis was scored 4, 7, 10, 14 , and 18 days after transfer to SIM or RIM. Symbols and vertical lines represent mean values and standard errors, respectively. Data were obtained from 3 sets of experiments. In each set, 20 explants were used for each culture condition (a) Shoot redif. from root explants

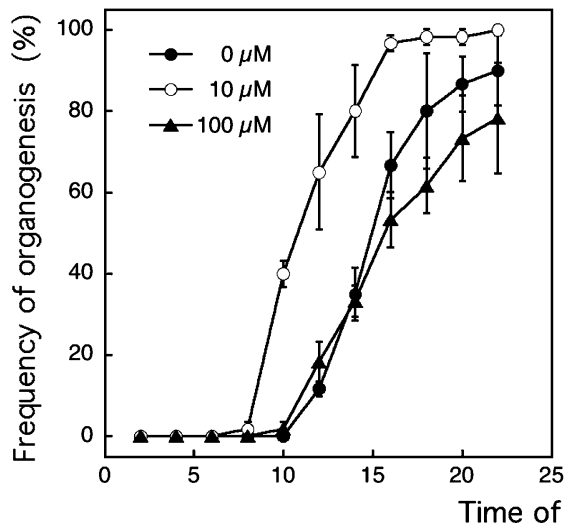

(b) Shoot redif. from hypocotyl explants

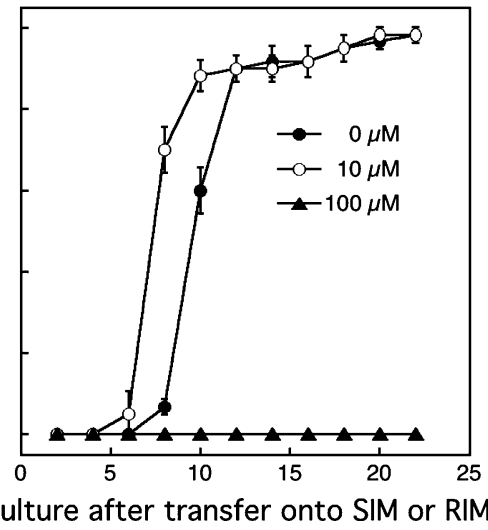

(c) Root redif. from hypocotyl explants

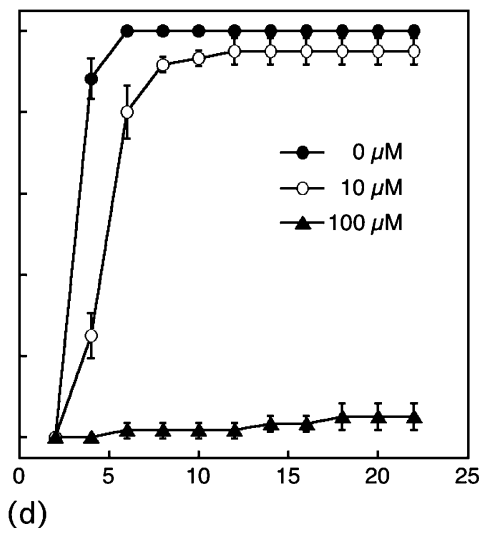

Fig. 2 Time course of organogenesis in vitro as influenced by BrdU pretreatment. (a) Shoot redifferentiation from root explants. (b) Shoot redifferentiation from hypocotyl explants. (c) Root redifferentiation from hypocotyl explants. Root explants $(a)$ and hypocotyl explants $(b, c)$ were precultured on CIM containing 0,10 , or $100 \mu \mathrm{M}$ BrdU for 4 days, and subsequently cultured on BrdU-free

shoots at high frequency under weak light, they rarely redifferentiated shoots in darkness. The requirement of shoot redifferentiation for light was reduced by the exposure of explants to $10 \mu \mathrm{M}$ BrdU during preculture on CIM, which significantly increased the frequency of shoot rediffer-
SIM $(a, b)$ or BrdU-free RIM $(c)$. Frequency of organogenesis was monitored after transfer to SIM or RIM. Symbols and vertical lines represent mean values and standard errors, respectively. Data were obtained from 3 sets of experiments. In each set, 20 explants were used for each culture condition

entiation in darkness. BrdU pretreatment at $100 \mu \mathrm{M}$ caused severe inhibition of shoot redifferentiation from hypocotyl explants. Thus, both promotive and inhibitory effects of BrdU pretreatment were observed in darkness as well as under light. 
Table 2 Effects of dT added with BrdU during preculture on organogenesis

\begin{tabular}{|c|c|c|c|c|c|c|}
\hline \multirow[t]{2}{*}{ Explants } & \multirow[t]{2}{*}{ Type of organogenesis } & \multirow[t]{2}{*}{ BrdU pretreatment $(\mu \mathrm{M})$} & \multirow[t]{2}{*}{$\mathrm{dT}$ addition $(\mu \mathrm{M})$} & \multicolumn{3}{|c|}{ Frequency of organogenesis $(\%)^{a}$} \\
\hline & & & & $10 \mathrm{~d}$ & $14 \mathrm{~d}$ & $21 \mathrm{~d}$ \\
\hline \multirow[t]{3}{*}{ Root } & \multirow[t]{3}{*}{ Shoot redifferentiation ${ }^{\mathrm{b}}$} & 0 & $\begin{array}{r}0 \\
10 \\
100\end{array}$ & $\begin{array}{l}6.7 \pm 1.9 \\
3.3 \pm 3.8 \\
0.0 \pm 0.0\end{array}$ & $\begin{array}{l}53.3 \pm 13.6 \\
43.3 \pm 16.4 \\
38.3 \pm 17.9\end{array}$ & $\begin{array}{l}93.3 \pm 7.5 \\
88.3 \pm 13.2 \\
93.3 \pm 7.5\end{array}$ \\
\hline & & 10 & $\begin{array}{r}0 \\
10 \\
100\end{array}$ & $\begin{array}{l}41.7 \pm 1.9 \\
43.3 \pm 13.2 \\
10.0 \pm 3.3\end{array}$ & $\begin{array}{l}93.3 \pm 3.8 \\
86.7 \pm 7.5 \\
63.3 \pm 21.7\end{array}$ & $\begin{array}{r}98.3 \pm 1.9 \\
100.0 \pm 0.0 \\
98.3 \pm 1.9\end{array}$ \\
\hline & & 100 & $\begin{array}{r}0 \\
10 \\
100\end{array}$ & $\begin{array}{r}6.7 \pm 5.0 \\
15.0 \pm 3.3 \\
10.0 \pm 8.6\end{array}$ & $\begin{array}{l}40.0 \pm 8.6 \\
48.3 \pm 5.0 \\
85.0 \pm 5.6\end{array}$ & $\begin{array}{l}68.3 \pm 6.9 \\
65.0 \pm 3.3 \\
96.7 \pm 3.8\end{array}$ \\
\hline \multirow[t]{3}{*}{ Hypocotyl } & \multirow[t]{3}{*}{ Shoot redifferentiation $^{\mathrm{b}}$} & 0 & $\begin{array}{r}0 \\
10 \\
100\end{array}$ & $\begin{array}{l}64.2 \pm 6.7 \\
51.7 \pm 13.2 \\
51.7 \pm 6.8\end{array}$ & $\begin{array}{l}90.0 \pm 5.6 \\
86.7 \pm 8.2 \\
88.3 \pm 7.5\end{array}$ & $\begin{array}{l}96.7 \pm 1.9 \\
98.3 \pm 1.9 \\
90.0 \pm 3.3\end{array}$ \\
\hline & & 10 & $\begin{array}{r}0 \\
10 \\
100\end{array}$ & $\begin{array}{l}70.0 \pm 6.5 \\
95.0 \pm 3.3 \\
80.0 \pm 3.3\end{array}$ & $\begin{array}{r}85.0 \pm 6.5 \\
96.7 \pm 1.9 \\
100.0 \pm 0.0\end{array}$ & $\begin{array}{r}88.3 \pm 6.8 \\
100.0 \pm 0.0 \\
100.0 \pm 0.0\end{array}$ \\
\hline & & 100 & $\begin{array}{r}0 \\
10 \\
100\end{array}$ & $\begin{array}{r}0.0 \pm 0.0 \\
0.0 \pm 0.0 \\
26.7 \pm 3.8\end{array}$ & $\begin{array}{r}0.0 \pm 0.0 \\
0.0 \pm 0.0 \\
45.0 \pm 8.6\end{array}$ & $\begin{array}{r}0.0 \pm 0.0 \\
0.0 \pm 0.0 \\
76.7 \pm 5.0\end{array}$ \\
\hline \multirow[t]{3}{*}{ Hypocotyl } & \multirow[t]{3}{*}{ Root redifferentiation $^{c}$} & 0 & $\begin{array}{r}0 \\
10 \\
100\end{array}$ & $\begin{array}{l}100.0 \pm 0.0 \\
100.0 \pm 0.0 \\
100.0 \pm 0.0\end{array}$ & & \\
\hline & & 10 & $\begin{array}{r}0 \\
10 \\
100\end{array}$ & $\begin{array}{r}98.3 \pm 1.9 \\
100.0 \pm 0.0 \\
100.0 \pm 0.0\end{array}$ & & \\
\hline & & 100 & $\begin{array}{r}0 \\
10 \\
100\end{array}$ & $\begin{array}{r}0.0 \pm 0.0 \\
5.0 \pm 5.6 \\
88.3 \pm 8.2\end{array}$ & & \\
\hline
\end{tabular}

Root and hypocotyl explants were precultured on CIM containing various concentrations of BrdU and dT for 4 days and subsequently cultured on SIM or RIM

${ }^{\text {a }}$ Mean value \pm standard error of percentages of explants undergoing organogenesis per total explants, which were scored 10 days, 14 days, and 21 days after transfer to SIM or RIM. Data were collected from 3 sets of experiments (20 explants for each culture condition in each set)

${ }^{\mathrm{b}}$ Culture on SIM

${ }^{\mathrm{c}}$ Culture on RIM

Phytohormone dependency of shoot redifferentiation in BrdU-pretreated explants

In general, the ratio of cytokinin to auxin is a critical determinant of organogenesis in plant tissue culture. To test the possibility that the dependency of shoot redifferentiation on these phytohormones is altered by BrdU, root and hypocotyl explants precultured with or without BrdU on CIM were cultured on modified SIM containing various concentrations of 2-iPA and IAA. The overall results showed that the phytohormone dependency of shoot redifferentiation was almost unchanged in root explants fed with $10 \mu \mathrm{M}$ or $100 \mu \mathrm{M}$ BrdU, and in hypocotyl explants fed with $10 \mu \mathrm{M}$ BrdU (Table 4). Under all phytohormone conditions, shoot redifferentiation from hypocotyl explants was strongly inhibited by pretreatment with $100 \mu \mathrm{M}$ BrdU. 
Table 3 Effects of BrdU pretreatment on shoot redifferentiation under different light conditions

\begin{tabular}{|c|c|c|c|c|}
\hline \multirow[t]{2}{*}{ Explants } & \multirow[t]{2}{*}{ Light condition } & \multirow[t]{2}{*}{ BrdU pretreatment $(\mu \mathrm{M})$} & \multicolumn{2}{|c|}{$\begin{array}{l}\text { Frequency of shoot red- } \\
\text { ifferentiation }(\%)^{\mathrm{a}}\end{array}$} \\
\hline & & & $14 \mathrm{~d}$ & $21 \mathrm{~d}$ \\
\hline \multirow[t]{3}{*}{ Root } & \multirow[t]{3}{*}{ Light } & 0 & 35.0 & 85.0 \\
\hline & & 10 & 85.0 & 100.0 \\
\hline & & 100 & 30.0 & 67.5 \\
\hline \multirow[t]{3}{*}{ Root } & \multirow[t]{3}{*}{ Dark } & 0 & 0.0 & 15.0 \\
\hline & & 10 & 52.5 & 62.5 \\
\hline & & 100 & 12.5 & 25.0 \\
\hline \multirow[t]{3}{*}{ Hypocotyl } & \multirow[t]{3}{*}{ Light } & 0 & 95.0 & 97.5 \\
\hline & & 10 & 87.5 & 97.5 \\
\hline & & 100 & 0.0 & 0.0 \\
\hline \multirow[t]{3}{*}{ Hypocotyl } & \multirow[t]{3}{*}{ Dark } & 0 & 45.0 & 62.5 \\
\hline & & 10 & 67.5 & 70.0 \\
\hline & & 100 & 0.0 & 0.0 \\
\hline
\end{tabular}

Root and hypocotyl explants were precultured on CIM containing 0, 10, or $100 \mu \mathrm{M}$ BrdU for 4 days and subsequently cultured on SIM containing $100 \mu \mathrm{M}$ dT. Cultures were carried out under weak light or in darkness

${ }^{a}$ Percentages of shoot-forming explants per total explants (40 explants for each condition) were scored 14 days and 21 days after transfer to SIM

\section{Discussion}

In the present study, we conducted a systematic survey of the influence of BrdU on plant organogenesis in vitro using the two-step culture system of Arabidopsis (Ozawa et al., 1998). In this system, root and hypocotyl explants are first precultured on CIM, during which time dedifferentiation and initiation of callus formation take place in the central cylinder. Explants are then cultured either on SIM to induce shoot redifferentiation or on RIM to induce root redifferentiation. Our results clearly showed that BrdU affected these two stages differently. When BrdU was administered after transfer onto SIM or RIM, BrdU simply exerted an inhibitory effect on all types of organogenesis. In contrast, the influence of BrdU temporally applied during CIM culture was far more complicated, with shoot redifferentiation being accelerated by BrdU pretreatment at $1-10 \mu \mathrm{M}$ in both root and hypocotyl explants. BrdU pretreatment at higher concentrations caused severe inhibition in hypocotyl explants, but not in root explants.

A most notable aspect of the effects of BrdU was the promotion of shoot redifferentiation following pretreatment with low-dose BrdU. Since BrdU-pretreated and untreated explants showed similar phytohormone dependencies for shoot redifferentiation, the accelerated shoot redifferentiation was unlikely to result from alterations to endogenous phytohormone contents and/or phytohormone responsiveness. As suggested in HeLa cells (Ogino et al., 2002; Suzuki et al., 2002), BrdU incorporation into DNA might lead to the alteration of chromatin structures and the resultant modification of gene expression profiles. Since BrdU incorporation photosensitizes DNA, photodamages to DNA can also affect gene expression when BrdU is administered under light. However, this is not the case for the effects of BrdU pretreatment on shoot redifferentiation because the effects were observed even in total darkness. Genes participating in the construction of the shoot apical meristem such as CUPSHAPED COTYLEDON, SHOOT-MERISTEMLESS, and WUSCHEL are expressed in association with shoot redifferentiation (Cary et al., 2002). Regardless of the mechanisms responsible for the effects of BrdU on shoot redifferentiation, expression analyses of these genes would be a promising way to gain molecular information about the BrdU action.

There are two possible explanations that may account for differences in the sensitivity to pretreatment with high-dose BrdU between root and hypocotyl explants. First, root explants may have a much smaller activity of BrdU uptake or a 
Table 4 Effects of BrdU pretreatment on the phytohormone dependency of shoot redifferentiation

\begin{tabular}{|c|c|c|c|c|c|c|}
\hline \multirow[t]{3}{*}{ Explants } & \multirow[t]{3}{*}{ BrdU pretreatment $(\mu \mathrm{M})$} & \multirow[t]{3}{*}{ IAA $\left(\mathrm{mg} \mathrm{l}^{-1}\right)$} & \multicolumn{4}{|c|}{ Frequency of shoot redifferentiation $(\%)^{\mathrm{a}}$} \\
\hline & & & \multicolumn{4}{|c|}{ 2-iPA $\left(\mathrm{mg} \mathrm{l}^{-1}\right)$} \\
\hline & & & 0 & 0.05 & 0.5 & 5 \\
\hline \multirow[t]{9}{*}{ Root } & \multirow[t]{3}{*}{0} & 0 & 0.0 & 33.3 & 36.7 & 43.3 \\
\hline & & 0.15 & 0.0 & 100.0 & 100.0 & 16.7 \\
\hline & & 1.5 & 0.0 & 66.7 & 100.0 & 56.7 \\
\hline & \multirow[t]{3}{*}{10} & 0 & 0.0 & 76.7 & 80.0 & 30.0 \\
\hline & & 0.15 & 0.0 & 86.7 & 96.7 & 83.3 \\
\hline & & 1.5 & 0.0 & 96.7 & 100.0 & 96.7 \\
\hline & \multirow[t]{3}{*}{100} & 0 & 0.0 & 76.7 & 73.3 & 3.3 \\
\hline & & 0.15 & 0.0 & 86.7 & 100.0 & 73.3 \\
\hline & & 1.5 & 0.0 & 100.0 & 93.3 & 60.0 \\
\hline \multirow[t]{9}{*}{ Hypocotyl } & \multirow[t]{3}{*}{0} & 0 & 0.0 & 80.0 & 96.7 & 53.3 \\
\hline & & 0.15 & 0.0 & 96.7 & 100.0 & 96.7 \\
\hline & & 1.5 & 0.0 & 96.7 & 100.0 & 96.7 \\
\hline & \multirow[t]{3}{*}{10} & 0 & 0.0 & 60.0 & 66.7 & 26.7 \\
\hline & & 0.15 & 0.0 & 70.0 & 90.0 & 60.0 \\
\hline & & 1.5 & 0.0 & 76.7 & 86.7 & 86.7 \\
\hline & \multirow[t]{3}{*}{100} & 0 & 0.0 & 3.3 & 0.0 & 0.0 \\
\hline & & 0.15 & 0.0 & 0.0 & 3.3 & 0.0 \\
\hline & & 1.5 & 0.0 & 0.0 & 13.3 & 0.0 \\
\hline
\end{tabular}

Root and hypocotyl explants were precultured on CIM containing 0,10 , or $100 \mu \mathrm{M}$ BrdU for 4 days and subsequently cultured on modified SIM containing $100 \mu \mathrm{M}$ dT and varioous concentrations of IAA and 2-iPA

a Percentages of shoot-forming explants per total explants (30 explants for each condition) were scored 21 days after transfer to SIM

much larger pool of dT, which would reduce the effectiveness of BrdU. However, this possibility can be ruled out based on the observation that shoot redifferentiation was accelerated by BrdU pretreatment at low concentrations similarly in root and hypocotyl explants. The other possible explanation is that a BrdU-sensitive event required for shoot redifferentiation is involved in the preculture stage of hypocotyl explants, but is absent in the preculture stage of root explants.

Phenotypic characterization of tissue culture responses of shoot redifferentiation defective (srd) mutants identified three states different in competence for cell proliferation and organogenesis: incompetent (IC), competent with respect to root redifferentiation (CR), and competent with respect to shoot and root redifferentiation (CSR) (Ozawa et al., 1998). Dedifferentiation of hypocotyl explants in the preculture stage was genetically dissected on the basis of the srd phenotypes into two phases, transition from IC to CR and transition from CR to CSR. The first phase is specific to hypocotyl dedifferentiation and the second phase is common to both root and hypocotyl dedifferentiation (Ozawa et al., 1998). During the first phase, hypocotyl explants, which are initially incompetent for cell proliferation, become competent with the aid of the SRD2 function to enter the CR state. In contrast, root explants, which are in the CR state at the initiation of culture, skip this phase and do not need the $S R D 2$ function for dedifferentiation. Further analysis of the SRD2 gene indicated that cell proliferation competence is linked with the level of snRNAs (Ohtani and Sugiyama, 2005). Therefore, assuming that high concentrations of BrdU interfere with the SRD2-mediated accumulation of snRNAs or some functions of the snRNAs, the different sensitivity of root and hypocotyl explants to BrdU can be accounted for reasonably. It should be noted that, according to this hypothesis, the inhibitory effect of high-dose BrdU in hypocotyl explants is not based on BrdU incorporation into the nuclear DNA associated with DNA replication because BrdU should act before the reentry of hypocotyl cells into the cell cycle. 


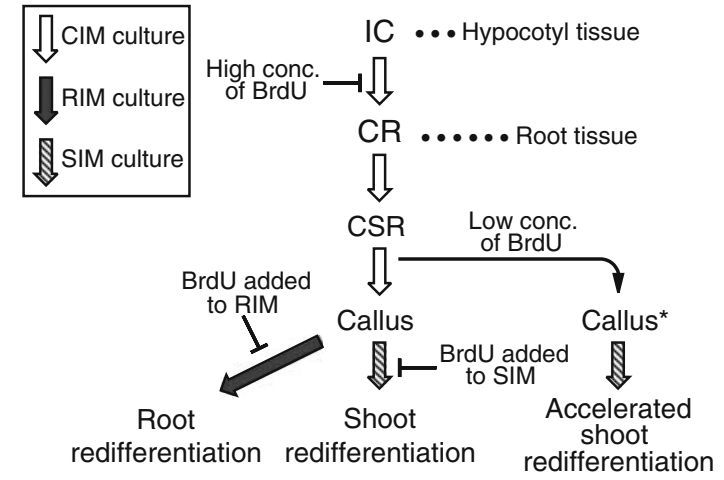

Fig. 3 Summary of BrdU effects on organogenesis in tissue culture of Arabidopsis. IC, incompetent with respect to cell proliferation and organogenesis; CR, competent with respect to root redifferentiation; CSR, competent with respect to shoot and root redifferentiation. Callus* represents callus containing BrdU-substituted DNA

Let us now return to the promotion of shoot redifferentiation by low concentrations of BrdU administered during the preculture stage. Since this effect was observed in root explants as well as hypocotyl explants, the BrdU action leading to the accelerated redifferentiation of shoots should be related to the second phase of dedifferentiation (transition from CR to CSR) or the following callus formation. We speculate that the DNA replication process during callus formation is closely associated with the promotive effect of BrdU, because it might be mediated by incorporation of BrdU into DNA as discussed in the previous paragraph. In summary, the full spectrum of BrdU effects on organogenesis in tissue culture of Arabidopsis can be depicted in Figure 3.

There are several papers reporting the effects of BrdU on particular aspects of development in various organisms, especially in animals. Although molecular mechanisms underlying these BrdU actions have not been investigated extensively and remain largely unknown, BrdU can potentially be very useful for the pharmacological analysis of developmental processes. Our findings provide a basis for future studies of plant organogenesis with BrdU as a pharmacological probe, which, in combination with molecular genetics using Arabidopsis mutants, would be effective in unraveling the hidden machinery of organogenesis.
Acknowledgment This work was supported in part by Grants-in-Aid from the Ministry of Education, Sports, Culture, Science and Technology of Japan (no.08740608).

\section{References}

Boyce R, Setlow R (1963) The action spectra for ultravioletlight inactivation of systems containing 5-bromouracilsubstituted deoxyribonucleic acid. I. Escherichia Coli $15 \mathrm{~T}^{-} \mathrm{A}^{-} \mathrm{U}^{-}$. Biochim Biophys Acta 68:446-454

Cary AJ, Che P, Howell SH (2002) Developmental events and shoot apical meristem gene expression patterns during shoot development in Arabidopsis thaliana. Plant J 32:867-877

Gamborg OL, Miller RA, Ojima K (1968) Nutrient requirement of suspension cultures of soybean root cells. Exp Cell Res 50:151-158

Gotô N, Hamada M (1988) Promotion of flowering by DNA base analogues and changes in acid phosphatase and peroxidase isozyme composition in darkgrown Arabidopsis thaliana. Plant Cell Physiol 29:683-688

Gratzner HG (1982) Monoclonal antibody to 5-bromoand 5-iododeoxyuridine: A new reagent for detection of DNA replication. Science 218:474-475

Konishi M, Sugiyama M (2003) Genetic analysis of adventitious root formation with a novel series of temperature-sensitive mutants of Arabidopsis thaliana. Development 130:5637-5647

Kuwagata M, Saito Y, Usumi K, Ono H, Nagao T (2001) Disruption of brain development in male rats exposed prenatally to 5-bromo-2'-deoxyuridine. Cong Anom 41:312-320

Luk DC, Bick MD (1977) Determination of 5'-bromodeoxyuridine in DNA by buoyant density. Anal Biochem 77:346-349

Morris SM (1991) The genetic toxicology of 5-bromodeoxyuridine in mammalian cells. Mutation Res 258:161-188

Murashige T, Skoog F (1962) A revised medium for rapid growth and bioassays with tobacco tissue cultures. Physiol Plant 15:473-497

Ogino H, Fujii M, Satou W, Suzuki T, Michishita E, Ayusawa D (2002) Binding of 5-bromouracil-containing S/MAR DNA to the nuclear matrix. DNA Res 9:25-29

Ohtani M, Sugiyama M (2005) Involvement of SRD2mediated activation of snRNA transcription in the control of cell proliferation competence in Arabidopsis. Plant J 43:479-490

Ozawa S, Yasutani I, Fukuda H, Komamine A, Sugiyama M (1998) Organogenic responses in tissue culture of srd mutants of Arabidopsis thaliana. Development 125:135-142

Puck TT, Kao F-T (1967) Genetics of somatic mammalian cells, V. Treatment with 5-bromodeoxyuridine and visible light for isolation of nutritionally deficient mutants. Proc Nat Acad Sci USA 58:1227-1234

Regan JD, Setlow RB, Ley RD (1971) Normal and defective repair of damaged DNA in human cells: 
A sensitive assay utilizing the photolysis of bromodeoxyuridine. Proc Nat Acad Sci USA 68:708-712

Shoji Y, Sugiyama M, Komamine A (1996) Suppression by 5-bromo-2'-deoxyuridine of transdifferentiation into tracheary elements of isolated mesophyll cells of Zinnia elegans. Plant Cell Physiol 37:401-403

Sugiyama M (2003) Isolation and initial characterization of temperature-sensitive mutants of Arabidopsis thaliana that are impaired in root redifferentiation. Plant Cell Physiol 44:588-596

Suzuki T, Michishita E, Ogino H, Fujii M, Ayusawa D (2002) Synergistic induction of the senescence-associated genes by 5-bromodeoxyuridine and AT-binding ligands in HeLa cells. Exp Cell Res 276:174-184
Thomas JC, Nessler C, Katterman F (1989) Interruption of somatic embryogenesis in Daucus carota L. by 5bromodeoxyuridine. Plant Physiol 90:921-927

Toné S, Tanaka S, Kato Y (1983) The inhibitory effect of 5-bromodeoxyuridine on the programmed cell death in the chick limb. Develop Growth Differ 25:381-391

Valvekens D, Van Montagu M, Van Lijsebettens M (1988) Agrobacterium tumefaciens-mediated transformation of Arabidopsis thaliana root explants by using kanamycin selection. Proc Natl Acad Sci USA 85:5536-5540

Yasutani I, Ozawa S, Nishida T, Sugiyama M, Komamine A (1994) Isolation of temperature-sensitive mutants of Arabidopsis thaliana that are defective in the redifferentiation of shoots. Plant Physiol 105:815-822 